\title{
Reusability of sewage sludge in clay bricks
}

\begin{abstract}
Bricks produced from sewage sludge in different compositions were investigated. Results of the tests indicated that the sludge proportion is a key factor in determining the brick quality. Increasing the sludge content results in a decrease in brick shrinkage, bulk density, and compressive strength. Brick weight loss on ignition was mainly due to the contribution of the contained organic matter from the sludge being burnt off during the firing process, as well as inorganic substances found in both clay and sludge. The physical, mechanical, and chemical properties of the bricks that were supplemented with various proportions of dried sludge from 10 to 40thinspwt\% and generally complied with the General Specification for Brick as per the Malaysian Standard MS 7.6:1972, which dictates the requirements for clay bricks used in walling in general. A standard leaching test method also showed that the leaching of metals from the bricks is very low.
\end{abstract}

Keyword: Sewage sludge, Clay bricks, Reusability, Malaysian Standard 